\title{
Morphologic changes of the saphenous vein Y-composite graft based on the left internal thoracic artery: 1-year intravascular ultrasound study
}

\author{
Ho Young Hwang, MD, PhD, ${ }^{a}$ Bon-Kwon Koo, MD, PhD, ${ }^{b}$ Se Jin Oh, MD, ${ }^{c}$ and Ki-Bong Kim, MD, PhD
}

Objective: We evaluated vessel wall characteristics and changes in the lumen diameter (LD) of saphenous vein (SV) conduits harvested with minimal manipulation and used as Y-composite grafts based on the in situ left internal thoracic artery (ITA) 1 year after coronary revascularization.

\begin{abstract}
Methods: Twenty-eight patients who underwent off-pump coronary revascularization using minimally manipulated SV Y-composite grafts were studied. Quantitative angiography was performed early and 1 year postoperatively to evaluate changes in the conduits. An intravascular ultrasound study of the proximal left ITA and SV conduits was also performed after 1-year postoperative angiography.

Results: The mean LD of the SV conduit decreased during the first year postoperatively ( $3.58 \pm 0.61 \mathrm{~mm}$ to $2.71 \pm$ $0.42 \mathrm{~mm} ; P<.001)$. The mean LD of the proximal left ITA increased $(2.41 \pm 0.25 \mathrm{~mm}$ to $2.63 \pm 0.30 \mathrm{~mm} ; P<.001)$, but was unchanged in the distal left ITA conduits. An intravascular ultrasound study demonstrated that the intimamedia (IM) thickness and the proportion of IM to vessel area were $0.31 \pm 0.12 \mathrm{~mm}$ and $29.1 \% \pm 8.3 \%$ in the SV, and $0.23 \pm 0.08 \mathrm{~mm}$ and $25.1 \% \pm 8.6 \%$ in the proximal left ITA, respectively. Absolute and percentage decreases in SV diameter were greater in SV grafts with a larger diameter initially and with single distal anastomosis than those without. However, those decreases did not result in an increased proportion of IM to vessel area.
\end{abstract}

Conclusions: Saphenous vein conduits harvested with minimal manipulation and used as Y-composite grafts based on the left ITA revealed decreased LD without accompanying abnormal IM thickening based on the flow requirements at 1 year postoperatively. (J Thorac Cardiovasc Surg 2015;149:487-93)

See related commentary on pages 494-5.

Supplemental material is available online.

The use of the saphenous vein (SV) as a coronary artery bypass conduit has limitations because of structural and functional differences between veins and arteries. ${ }^{1}$ Lower long-term graft patency rates and poorer clinical outcomes have been reported after coronary artery bypass grafting (CABG) using aortocoronary SV grafts compared with CABG using arterial grafts such as the internal thoracic artery (ITA) and

\footnotetext{
From the Department of Thoracic and Cardiovascular Surgery ${ }^{\mathrm{a}}$ and Division of Cardiology, ${ }^{\mathrm{b}}$ Department of Internal Medicine, Seoul National University Hospital, and Department of Thoracic and Cardiovascular Surgery, ${ }^{\mathrm{c}}$ Seoul National University Boramae Hospital, Seoul, Korea.

This work was supported by grants from Seoul National University Hospital (04-2011-018-0).

Disclosures: Authors have nothing to disclose with regard to commercial support.

H.Y.H. and B.-K.K. contributed equally to the study.

Received for publication June 8, 2014; revisions received Aug 7, 2014; accepted for publication Aug 18, 2014; available ahead of print Oct 8, 2014.

Address for reprints: Ki-Bong Kim, MD, PhD, Department of Thoracic and Cardiovascular Surgery, Seoul National University Hospital, 101 Daehak-ro, Jongno-gu, Seoul 110-744, Korea (E-mail: ckrym@yahoo.co.kr). $0022-5223 / \$ 36.00$

Copyright (c) 2015 by The American Association for Thoracic Surgery http://dx.doi.org/10.1016/j.jtcvs.2014.08.056
}

right gastroepiploic artery. ${ }^{2-4}$ However, the SV is still widely used as a bypass conduit because of its numerous advantages, including ease of access and manipulation, sufficient length for grafting, and short harvesting time.

Among the various efforts to overcome poor long-term patency of SV conduits, a minimal manipulation harvesting technique of the SV has been shown to be beneficial for endothelial preservation. Recent studies have demonstrated favorable results after off-pump CABG (OPCAB) using a minimally manipulated SV as a Y-composite graft in terms of endothelial preservation and angiographic patency. ${ }^{5-7}$

The aims of this study were to (1) evaluate the characteristics of the vessel wall and changes in the lumen diameter (LD) of minimally manipulated SV conduits used as Y-composite grafts, and (2) compare the changes in SV conduits with those of the left ITA, using serial quantitative coronary angiogram (QCA) studies performed early and 1 year postoperatively and intravascular ultrasound (IVUS) studies at 1 year after CABG.

\section{MATERIALS AND METHODS \\ Patient Characteristics}

The study protocol was approved by the Institutional Review Board (Approval Number: H-1109-089-378) and informed consent was obtained from all study participants.

From January 2010 to December 2011, 143 patients aged less than 75 years underwent isolated OPCAB using an SV Y-composite graft based on the in situ left ITA. Graft patency in all patients was confirmed by 


$$
\begin{array}{ll}
\text { Abbreviations and Acronyms } \\
\text { BMI } & =\text { body mass index } \\
\text { CABG } & =\text { coronary artery bypass grafting } \\
\text { IM } & =\text { intima-media } \\
\text { ITA } & =\text { internal thoracic artery } \\
\text { IVUS } & \text { intravascular ultrasound } \\
\text { LD } & =\text { lumen diameter } \\
\text { OPCAB } & =\text { off-pump coronary artery bypass grafting } \\
\text { QCA } & =\text { quantitative coronary angiogram } \\
\text { SV } & =\text { saphenous vein }
\end{array}
$$

coronary angiography performed before discharge. Of 120 patients who underwent 1-year postoperative coronary angiography as a part of the routine postoperative follow-up evaluation, regardless of the patient's anginal symptoms, 93 were eligible for the study protocol, which included QCA and IVUS. Twenty-seven patients were excluded ( 9 with malignant or major aortic diseases, 8 with chronic renal failure, 5 with 1 or more occluded distal anastomoses at early angiography, 3 with 2 or more occlusions of the sequential SV anastomoses at angiography at 1 year, and 2 who underwent percutaneous coronary intervention). However, only 35 patients consented to the study protocol. Seven of these patients were excluded because the IVUS image quality was inadequate for precise threedimensional analysis. Therefore, coronary angiograms and IVUS images from 28 patients were used for the final analysis. The mean age of the 28 patients at surgery was $62.1 \pm 11.0$ years. Preoperative characteristics were similar between the 28 patients in the study and the other 115 patients who underwent OPCAB (Table 1).

\section{Operative Techniques and Grafting Strategy}

The basic surgical procedures and principles of OPCAB and the SV harvesting technique have been previously described. ${ }^{5,8}$ The left ITA was harvested using a skeletonization technique. The SV was harvested as a second graft to be anastomosed to the side of the in situ left ITA to construct a Y-composite graft. The SV from the lower leg rather than the upper leg was preferred to avoid a possible size mismatch with native coronary arteries or the ITA. Harvesting of the SV was initiated after systemic heparinization. Manipulation and tension on the SV were minimized during harvesting, and manual intraluminal dilation was avoided. Immediately after the SV was harvested, it was anastomosed to the side of the in situ left ITA without any pharmacologic treatment. After the Y-composite graft was constructed, the distal end of the SV was clamped with an atraumatic bulldog (Scanlan International Inc, St. Paul, Minn) and left to be dilated spontaneously by the native flow and pressure of the left ITA until grafting was performed.

The left anterior descending coronary artery territory was revascularized first with the left ITA conduit. The left circumflex coronary artery territory was then revascularized with the SV conduit, followed by the right coronary artery territory. A sequential anastomotic technique using each arm of the Y-composite graft was used when more than 2 coronary arterial anastomoses were needed. The average number of distal anastomoses for the SV and left ITA conduits was $2.5 \pm 0.7$ and $1.1 \pm 0.3$, respectively.

Patients were anticoagulated with an initial dose of $1.5 \mathrm{mg} / \mathrm{kg}$ of heparin and received supplemental doses to maintain an activated clotting time longer than 300 seconds during $\mathrm{OPCAB}$. All patients received aspirin therapy $(200 \mathrm{mg} / \mathrm{d})$ until the day of surgery, which was resumed as soon as possible after surgery, usually 1 day postoperatively. Ticlopidine hydrochloride $(200 \mathrm{mg} / \mathrm{d})$ was used simultaneously with aspirin for 2 postoperative months. If the patient had a high level of low-density lipoprotein cholesterol (>100 mg/dL), statin therapy was initiated.
TABLE 1. Preoperative characteristics and risk factors of the study patients

\begin{tabular}{lccc}
\hline & $\begin{array}{c}\text { Study } \\
\text { patients } \\
(\mathbf{n}=\mathbf{2 8})\end{array}$ & $\begin{array}{c}\text { Other } \\
\text { patients } \\
(\mathbf{n}=\mathbf{1 1 5})\end{array}$ & $\begin{array}{c}\boldsymbol{P} \\
\text { value }\end{array}$ \\
\hline Age, y (mean $\pm \mathrm{SD})$ & $62.2 \pm 11.0$ & $63.7 \pm 9.2$ & .443 \\
Male:female & $21: 7$ & $88: 27$ & .865 \\
BMI, kg/m ${ }^{2}$ (mean $\left.\pm \mathrm{SD}\right)$ & $25.6 \pm 2.5$ & $24.9 \pm 2.9$ & .234 \\
Logistic EuroSCORE, & $2.2(0.88-17.2)$ & $2.6(0.88-69.55)$ & .267 \\
$\quad$ median (range) & & & \\
Risk factors, $(\%)$ & $15(53.6)$ & $52(45.2)$ & .427 \\
Smoking & $18(64.3)$ & $79(68.7)$ & .654 \\
Hypertension & $11(39.3)$ & $57(49.6)$ & .329 \\
Diabetes mellitus & $6(21.4)$ & $16(13.9)$ & .381 \\
History of stroke & $1(3.6)$ & $13(11.3)$ & .304 \\
Chronic renal failure & $13(46.4)$ & $39(33.9)$ & .217 \\
Dyslipidemia & $5(17.9)$ & $17(14.8)$ & .770 \\
History of PCI & $1(3.6)$ & $19(16.5)$ & .125 \\
Left ventricular dysfunction & & & \\
Angiographic diagnosis, $\mathrm{n}(\%)$ & & & .230 \\
$\quad$ Left main disease & $8(28.6)$ & $47(41.4)$ & .676 \\
Three-vessel disease & $22(78.6)$ & $86(75.0)$ & \\
\hline
\end{tabular}

$S D$, Standard deviation; $B M I$, body mass index; $P C I$, percutaneous coronary intervention; EuroSCORE, European System for Cardiac Operative Risk Evaluation.

\section{Angiography and QCA}

Early and 1-year postoperative angiography was performed at $1.2 \pm 0.5$ days and $12.9 \pm 1.1$ months postoperatively, respectively. Patency rates of the left ITA and SV grafts in the 35 patients enrolled in the study at 1 year were $100 \%$ (35 of 35 distal anastomoses) and 97.8\% (87 of 89 ), respectively. Two patients with 1 occluded far distal anastomosis of 3 or more sequential SV were included in the subsequent analyses. After diagnostic angiography, the left ITA was engaged using a 6-Fr guiding catheter and reference images were acquired after the administration of 100 to $200 \mu \mathrm{g}$ of nitroglycerin. A single experienced observer, who was blinded to the IVUS findings and blinded to the purpose of this study, performed QCA using the guiding catheter for calibration and an edge detection system (CAAS 5.7 QCA system, Pie Medical, Maastricht, the Netherlands). The target areas for QCA were 5-cm segments of the SV conduit distal to the Y-anastomosis site and the left ITA conduit proximal and distal to the Y-anastomosis site. After exclusion of $1 \mathrm{~cm}$ of the segments proximal and distal to the Y-anastomosis site, QCA was performed for the remaining 4-cm segments of each target vessel. The SV and proximal and distal left ITA segments analyzed by QCA were $40.2 \pm 0.2 \mathrm{~mm}, 39.0 \pm 0.8 \mathrm{~mm}$, and $40.1 \pm 0.4 \mathrm{~mm}(P=.191)$ in length, respectively, on the early postoperative angiogram; and $39.6 \pm 2.0 \mathrm{~mm}$, $39.7 \pm 1.3 \mathrm{~mm}$, and $40.1 \pm 0.2 \mathrm{~mm}(P=.291)$, respectively, on the 1 -year angiogram. The maximal, minimal, and mean LD of the SV and the proximal and distal left ITA segments were assessed.

\section{Intravascular Ultrasonographic Study}

The IVUS study was performed after the completion of angiography 1 -year postoperatively. The IVUS was performed in a standard fashion using an automated motorized pullback system $(0.5 \mathrm{~mm} / \mathrm{s})$ with commercially available imaging catheters (Boston Scientific/SCIMED, Minneapolis, Minn). The IVUS images were acquired after the administration of 100 to $200 \mu \mathrm{g}$ of nitroglycerin. The IVUS catheter was advanced into the SV conduit connected to the mid-portion of the left ITA and located at around $5 \mathrm{~cm}$ distal to the Y-anastomosis and an automated motorized pullback was performed for the total length of $10 \mathrm{~cm}$. 

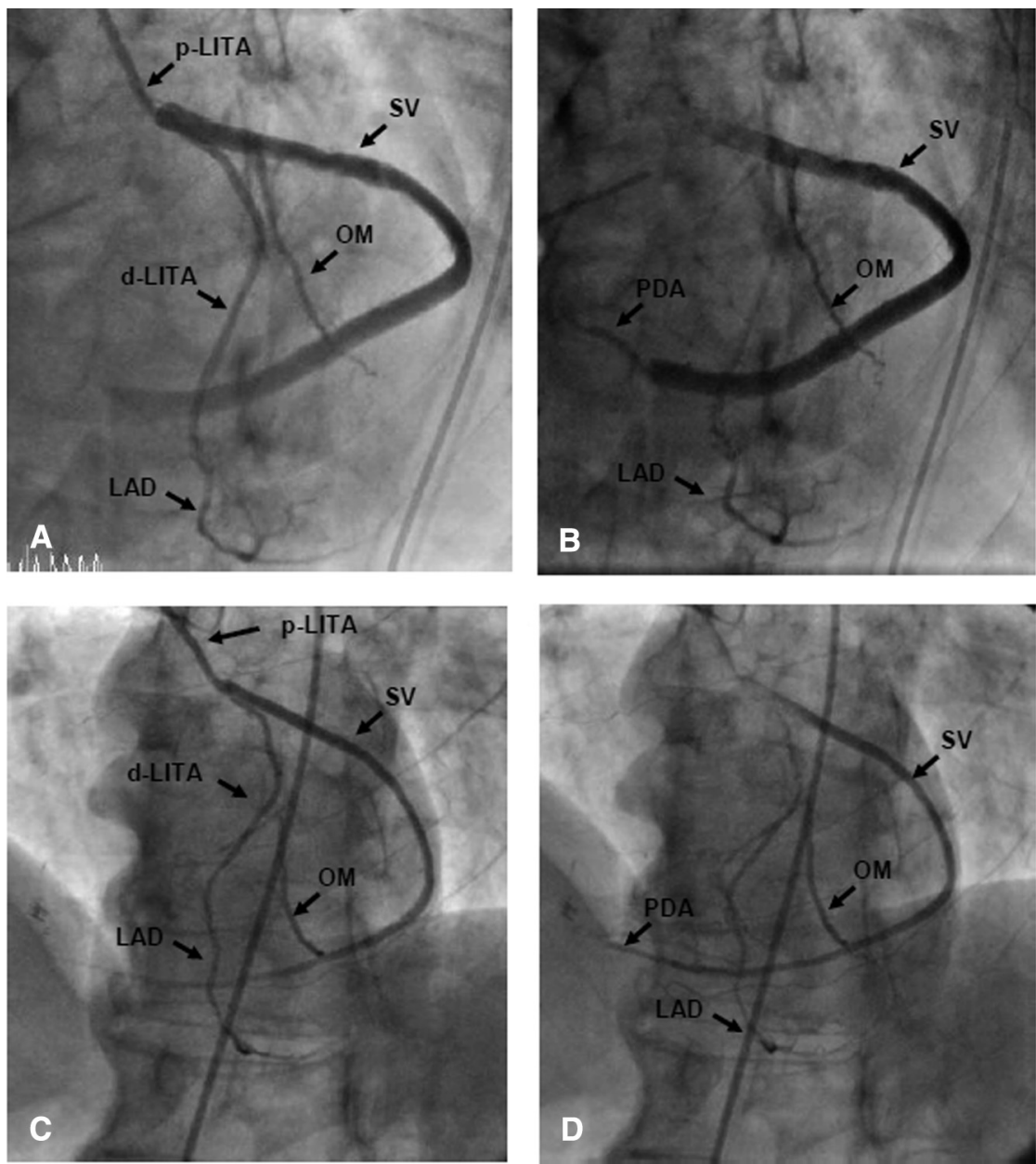

FIGURE 1. Measurement of the luminal diameter of the saphenous vein and the proximal and distal parts of the left internal thoracic artery composite grafts using the quantitative coronary angiographies performed early (A and B) and 1 year (C and D) after coronary artery bypass grafting in a 70-year old man. The mean diameter of the saphenous vein decreased from $4.53 \mathrm{~mm}$ to $2.83 \mathrm{~mm}$ during the first year after coronary artery bypass grafting. p-LITA, Proximal left internal thoracic artery; $d$-LITA, distal left internal thoracic artery; SV, saphenous vein; OM, obtuse marginal coronary artery; $L A D$, left anterior descending coronary artery; $P D A$, posterior descending coronary artery.

To avoid the influence of suture materials, the areas $1 \mathrm{~cm}$ proximal and distal from the Y-anastomosis were excluded from the analysis. IVUS images were obtained for $34.7 \pm 6.4 \mathrm{~mm}$ in the $\mathrm{SV}$ and $32.7 \pm 11.6 \mathrm{~mm}$ in the left ITA segments. The IVUS analysis was performed by 1 independent experienced observer blinded to the QCA information. Quantitative analyses of the IVUS data were performed using computerized planimetry software (echoPlaque 3.0, Indec Systems Inc, Santa Clara, Calif).

The lumen and vessel areas were measured every 1 millimeter. All volumes were calculated using the Simpson rule and then normalized for analyzed length. The area of intima-media (IM) was calculated by subtracting the luminal area from the vessel area. The proportion of IM area to vessel area was also calculated.

\section{Statistical Analysis}

Statistical analysis was performed with the SPSS software package (version 12.0; SPSS Inc, Chicago, Ill). Data were expressed as the mean \pm standard deviation, median and range, or proportion. Comparisons between the 2 groups were made using the $\chi^{2}$ test and the Fisher exact test for categorical variables and the Student $t$ test for continuous variables. Changes in the LD of the grafts were compared using the paired $t$ test. The Pearson correlation coefficient ( $r$ ) was used to evaluate the relationships between the continuous variables measured by the QCA and IVUS. Multivariable analyses for continuous dependent variables were performed using multiple regression analysis. Variables with a $P$ value less than .1 in the univariate analyses were entered into the multivariable analyses. Residual analyses were performed to assess modeling assumptions.

\section{RESULTS \\ QCA Study: Changes in the LD of the Bypass Conduits During the First Year After CABG}

The QCA study in the 28 patients revealed that the mean internal LD of the SV segments and the proximal and distal segments of the left ITA from the Y-anastomosis were $3.58 \pm 0.61 \mathrm{~mm}, 2.41 \pm 0.25 \mathrm{~mm}$, and $2.13 \pm 0.30 \mathrm{~mm}$, respectively, on the early postoperative angiogram. On the 1-year angiogram, the mean LD of the SV segments was significantly decreased compared with the early postoperative angiogram $(2.71 \pm 0.42 \mathrm{~mm}$, absolute 

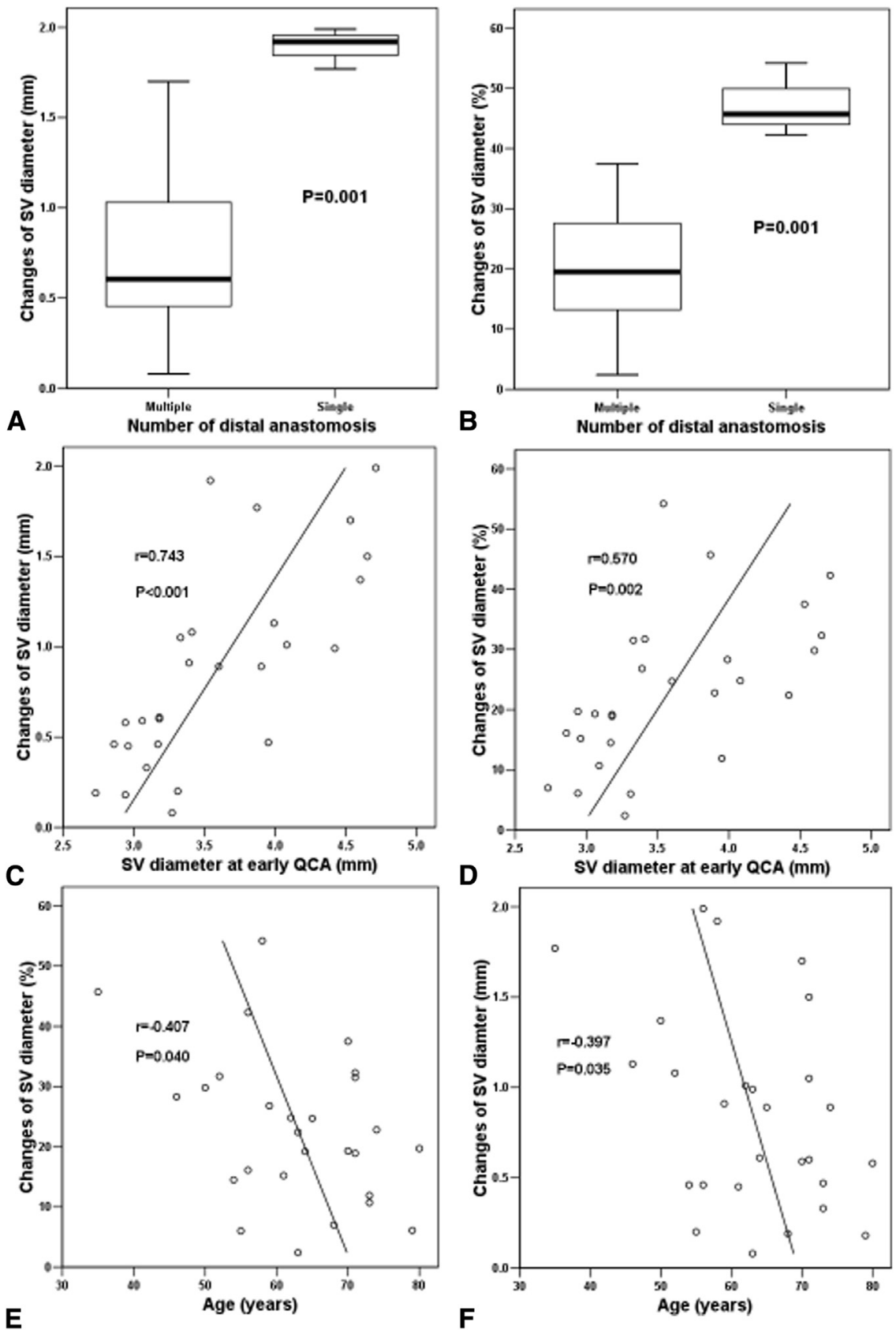

FIGURE 2. Absolute and percentage decreases in the diameter of the saphenous vein according to the number of distal anastomoses (A and B), age $(\mathrm{C}$ and $\mathrm{D})$, and the diameter of the saphenous vein at the early quantitative coronary angiography (E and F). SV, Saphenous vein; $Q C A$, quantitative coronary angiography.

difference $=-0.87 \pm 0.55 \mathrm{~mm}$, percentage change $=-23.0 \% \pm 12.7 \% ; P<.001)$. The mean LD of the proximal left ITA segments increased significantly to $2.63 \pm 0.30 \mathrm{~mm}$ (absolute difference $=0.22 \pm 0.29 \mathrm{~mm}$, percentage change $=9.5 \% \pm 10.9 \% ; P<.001$ ), However, the mean LD of the distal left ITA segments remained unchanged $(2.10 \pm 0.35 \mathrm{~mm}$, absolute difference $=-0.04$ $\pm 0.30 \mathrm{~mm}$, percentage change $=-2.9 \% \pm 2.5 \%$; $P=.566$ ) (Table E1, Figure 1, and Figure E1).
Factors associated with the decrease in the SV LD during the first postoperative year were analyzed by including all preoperative variables shown in Table 1 and the early QCA results. In the univariate analyses, the absolute decrease in the diameter of the SV segment was greater in young patients $(P=.040)$, and patients with a large LD of the SV segment at early postoperative QCA $(P<.001)$. The decrease was also greater in patients undergoing single distal anastomosis by the SV conduit than in patients 
TABLE 2. Multivariable analyses for factors associated with a decrease in the diameter of saphenous vein composite grafts 1 year after coronary artery bypass grafting

\begin{tabular}{lccccc}
\hline & \multicolumn{2}{c}{ Univariate } & & \multicolumn{2}{c}{ Multivariable } \\
\cline { 2 - 3 } \cline { 5 - 6 } & $\begin{array}{c}\beta \pm \text { standard } \\
\text { error }\end{array}$ & $\begin{array}{c}\boldsymbol{P} \\
\text { value }\end{array}$ & $\begin{array}{c}\boldsymbol{\beta} \pm \text { standard } \\
\text { error }\end{array}$ & $\begin{array}{c}\boldsymbol{P} \\
\text { value }\end{array}$ \\
\hline Factors associated with & an absolute decrease in the SV diameter & \\
Age in years & $-0.021 \pm 0.010$ & .040 & $-0.001 \pm 0.006$ & .927 \\
Smoking & $0.382 \pm 0.203$ & .072 & $0.078 \pm 0.119$ & .519 \\
Single distal & $1.155 \pm 0.257$ & .001 & $0.861 \pm 0.194$ & $<.001$ \\
$\quad$ anastomosis & & & & \\
SV diameter at & $0.679 \pm 0.122$ & $<.001$ & $0.526 \pm 0.100$ & $<.001$ \\
$\quad$ early QCA & & & & \\
Factors associated with a percentage decrease in the SV diameter & \\
Age in years & $-0.493 \pm 0.221$ & .035 & $-0.069 \pm 0.172$ & .736 \\
Single distal & $27.417 \pm 5.696$ & .001 & $22.015 \pm 5.664$ & .001 \\
$\quad$ anastomosis & & & & \\
SV diameter at early & $11.914 \pm 3.431$ & .002 & $8.454 \pm 2.739$ & .005 \\
$\quad$ QCA & & & & \\
\hline
\end{tabular}

$S V$, Saphenous vein; $Q C A$, quantitative coronary angiography. $*$ All factors from the preoperative data and the early QCA results were analyzed and only variables that entered into the multivariable analyses were demonstrated.

undergoing multiple distal anastomoses by a sequential SV grafting technique $(P=.001)$. The percentage decrease in the LD of the SV segment was also associated with patient age, initial diameter of the SV, and single distal anastomosis $(P=.035, .002$, and .001 , respectively; Figure 2). In the multivariable analyses, the absolute and percentage decreases in the LD of the SV segment were greater in patients with single distal SV anastomosis and large LD of the SV conduit in the early postoperative QCA study (Table 2).

\section{Comparison of QCA and IVUS for Measuring the LD}

The mean LDs of the SV and proximal left ITA segments were $3.19 \pm 0.43 \mathrm{~mm}$ and $2.97 \pm 0.32 \mathrm{~mm}$, respectively, at the 1-year IVUS study. There was a strong correlation between the mean LDs measured by IVUS and QCA $(r=0.868$ for the SV and $r=0.770$ for the left ITA; Figure E2).

\section{Intravascular Ultrasound Study}

None of the patients experienced IVUS-related complications such as chest pain, myocardial infarction, or conduit injury. Vessel area, IM area, and the proportion of the IM area were $11.60 \pm 3.41 \mathrm{~mm}^{2}, 3.49 \pm 1.75$ $\mathrm{mm}^{2}$, and $29.1 \% \pm 8.3 \%$, respectively, in the SV segments, and $9.25 \pm 1.49 \mathrm{~mm}^{2}, 2.30 \pm 0.78 \mathrm{~mm}^{2}$, and $25.1 \% \pm 8.6 \%$, respectively, in the proximal left ITA segments. The proportion of the IM area was not significantly different between the SV and left ITA segments $(P=.091$; Figure 3). Mean vessel diameter, LD, and IM thickness were $3.81 \pm 0.57 \mathrm{~mm}, 3.19 \pm 0.43 \mathrm{~mm}$, and $0.31 \pm 0.12$ $\mathrm{mm}$, respectively, in the SV segments, and $3.43 \pm 0.28$ $\mathrm{mm}, 2.97 \pm 0.32 \mathrm{~mm}$, and $0.23 \pm 0.08 \mathrm{~mm}$, respectively,

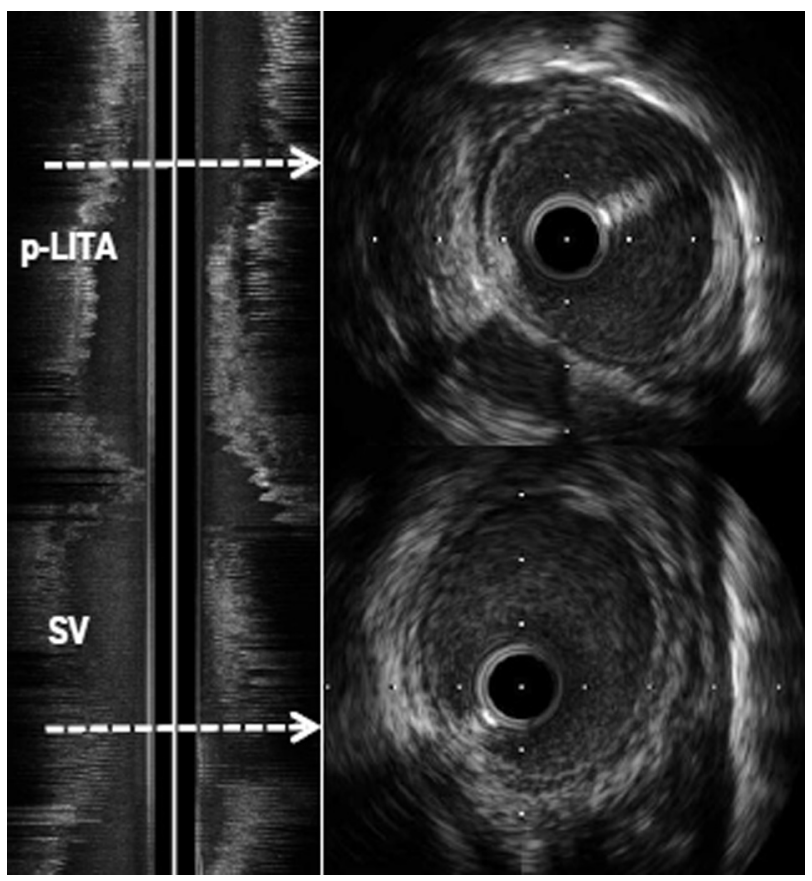

FIGURE 3. Images of intravascular ultrasonography of the proximal left internal thoracic artery and saphenous vein in the same patient as in Figure 1. The lumen of the proximal left internal thoracic artery and saphenous vein show a thin intima-media without abnormal plaques. $p$-LITA, Proximal left internal thoracic artery; $S V$, saphenous vein.

in the left ITA segments. The ratio of IM thickness to vessel diameter was also not statistically different between the SV and left ITA segments $(P=.096)$ (Table 3$)$.

Factors associated with the increased proportion of the IM area of the SV were analyzed by including all preoperative variables and the early QCA results. In the univariate analyses, the increased proportion of the IM area of the SV segments did not correlate with the absolute and percentage decreases in the LD of the SV segment $(\mathrm{r}=-0.220, P=.270$ and $\mathrm{r}=-0.178, P=.375$, respectively). Univariate analysis demonstrated that body mass index $\left(>25 \mathrm{~kg} / \mathrm{m}^{2}\right)$ and single distal SV anastomosis had a marginally significant association with the increased proportion of IM area; however, the multivariable analysis failed to demonstrate any independent factor for the increased proportion of IM area (Table 4).

\section{DISCUSSION}

The present study revealed 2 main findings. First, the mean LD of SV composite grafts based on the left ITA decreased significantly during the first year after CABG. Second, the proportion of IM area and the ratio of IM thickness in the SV composite grafts were not different from those in the left ITA at the 1-year IVUS study. Therefore, the SV composite grafts went through a process of advantageous negative remodeling during the first postoperative year. 
TABLE 3. Intravascular ultrasonographic data on the saphenous vein and left internal thoracic artery at 1 year after coronary artery bypass grafting in 28 patients

\begin{tabular}{lccc}
\hline & Saphenous vein & Left ITA & P value [95\% CI of difference] \\
\hline Vessel area, $\mathrm{mm}^{2} \pm \mathrm{SD}$ & $11.60 \pm 3.41$ & $9.25 \pm 1.49$ & - \\
Luminal area, $\mathrm{mm}^{2} \pm \mathrm{SD}$ & $8.11 \pm 2.10$ & $6.95 \pm 1.50$ & - \\
$\mathrm{IM}$ area, $\mathrm{mm}^{2} \pm \mathrm{SD}$ & $3.49 \pm 1.75$ & $2.30 \pm 0.78$ & - \\
Proportion of the intimal area, \% $\pm \mathrm{SD}$ & $29.1 \pm 8.3$ & $25.1 \pm 8.6$ & $.091[-8.691,0.690]$ \\
Vessel diameter, $\mathrm{mm} \pm \mathrm{SD}$ & $3.81 \pm 0.57$ & $3.43 \pm 0.28$ & - \\
Luminal diameter, $\mathrm{mm} \pm \mathrm{SD}$ & $3.19 \pm 0.43$ & $2.97 \pm 0.32$ & - \\
IM thickness, $\mathrm{mm} \pm \mathrm{SD}$ & $0.31 \pm 0.12$ & $0.23 \pm 0.08$ & - \\
Ratio of the IM thickness to the vessel diameter, \% $\pm \mathrm{SD}$ & $15.91 \pm 5.00$ & $13.55 \pm 5.08$ & $.096[-5.176,0.447]$ \\
\hline
\end{tabular}

ITA, Internal thoracic artery; $C I$, confidence interval; $S D$, standard deviation; $I M$, intima-media.

Lower long-term graft patency rates and worse clinical outcomes have been reported after CABG using aortocoronary SV grafts compared with CABG using arterial grafts, such as the left and right ITAs and right gastroepiploic artery. ${ }^{2-4}$ However, the SV is still widely used for grafting because of its numerous advantages, including ease of access and manipulation, sufficient length for grafting, and short harvesting time. The patency of an SV graft is influenced by 3 processes: thrombosis, fibrointimal hyperplasia, and atherosclerosis. ${ }^{9}$ Fibrointimal hyperplasia or neointima formation is believed to be an adaptive mechanism to normalize shear stress by reducing the LD. ${ }^{10}$ It occurs several months to years after CABG and works as a template for later atherosclerosis of the vein.

Previous IVUS studies have demonstrated that diseased native coronary arteries and SV bypass grafts undergo both positive and negative remodeling in response to accumulation of atherosclerotic plaque. ${ }^{11,12}$ With regard to the remodeling changes in angiographically normal aortocoronary SV grafts approximately 1 year after CABG, several studies have reported conflicting results. ${ }^{13-15}$ By serially analyzing $15 \mathrm{SV}$ grafts from 12 patients, previous IVUS study demonstrated that intimal thickness and intimal area increased significantly 12 months postoperatively compared with 1 month postoperatively. ${ }^{13}$ In a different IVUS study, a nonserial comparison performed in the 2 different subgroup populations showed that SV vessel wall thickness increased significantly late postoperatively (6-24 months) compared with early postoperatively

TABLE 4. Multivariable analyses for factors associated with the proportion of the intimal area of the saphenous vein composite graft at the 1-year intravascular ultrasonographic study

\begin{tabular}{|c|c|c|c|c|}
\hline \multirow[b]{2}{*}{ Variables* } & \multicolumn{2}{|c|}{ Univariate } & \multicolumn{2}{|c|}{ Multivariable } \\
\hline & $\begin{array}{c}\beta \pm \text { standard } \\
\text { error }\end{array}$ & $\begin{array}{c}P \\
\text { value }\end{array}$ & $\begin{array}{c}\beta \pm \text { standard } \\
\text { error }\end{array}$ & $\begin{array}{c}P \\
\text { value }\end{array}$ \\
\hline $\begin{array}{l}\text { Overweight } \\
\qquad\left(\mathrm{BMI}>25 \mathrm{~kg} / \mathrm{m}^{2}\right)\end{array}$ & $5.987 \pm 3.109$ & .065 & $4.785 \pm 3.147$ & .141 \\
\hline Single distal anastomosis & $9.129 \pm 4.828$ & .070 & $7.215 \pm 4.876$ & .15 \\
\hline
\end{tabular}

BMI, Body mass index. *All factors from the preoperative data and the early quantitative coronary angiography results were analyzed and only variables that entered into the multivariable analyses were demonstrated.
( $\leq 1$ month).${ }^{14}$ Another study demonstrated that total vessel diameter and wall thickness of patent SV grafts decreased significantly in serial multislice computed tomographic angiograms performed at 1 and 12 months postoperatively. ${ }^{15}$ However, no previous IVUS studies have examined SV conduits used as Y-composite grafts based on the left ITA.

An improved graft patency rate has been demonstrated with a minimally manipulative surgical technique for harvesting the SV. ${ }^{16}$ Grafting strategies of using the SV conduit as a Y-composite graft in addition to a minimally manipulative harvesting technique have been shown to be beneficial in terms of endothelial preservation and favorable patency rates. ${ }^{5-7}$ Theoretic advantages of using the SV as a composite graft based on the in situ left ITA are (1) exposure of the SV to less circulatory stress than a conduit anastomosed to the ascending aorta and (2) continuous exposure of the SV to endothelium-protective substances such as nitric oxide released from the in situ left ITA. ${ }^{17-19}$ In an IVUS study where the SV was harvested with its pedicle of surrounding tissue using a no-touch technique, the no-touch aortocoronary SV showed less intimal thickness and larger graft lumen volume than the conventional technique SV at 18 months postoperatively. ${ }^{20}$ Another recent study found decreased vascular smooth muscle cell activation in the no-touch SV compared with the conventionally harvested SV. ${ }^{21}$ In contrast, the present study demonstrated that the mean SV LD decreased significantly during the first year after CABG, although a similar finding of no abnormal intimal thickening was observed. The absolute and percentage decreases in the SV diameter were lower when the SV was used for multiple distal anastomoses by a sequential technique. In addition, the mean LD of the proximal left ITA increased significantly but remained unchanged in the distal left ITA. These findings suggest that both ITA and SV composite grafts have an adaptability to allow increased flow in response to changes in coronary vascular resistance.

The current study is the first IVUS study of the SV conduit used as a Y-composite graft. The absolute values of the IM area and IM thickness of the SV composite graft were smaller than those of aortocoronary SV conduits 
presented in previous studies although we were unable to perform statistical comparisons. ${ }^{13,15,20,22}$ A minimally manipulated SV composite graft based on the left ITA might result in advantageous negative SV graft remodeling during the first postoperative year. This remodeling and preserved endothelial function may have important roles in improving the patency rates of $\mathrm{SV}$ composite grafts as demonstrated in our recent study. ${ }^{23}$

\section{Study Limitations}

There are several limitations to the present study that must be recognized. First, the sample size was relatively small and serial IVUS studies were not performed because of fear of trauma to the conduits in the early postoperative period. Power calculations for any end points to determine the sample size were unrealistic and not performed in this invasive IVUS study. Instead, we assumed a total enrollment of 35 patients, and allowed for a withdrawal rate of approximately $30 \%$ during the study and image acquisition to reach our intended number of patients (25). Second, this study was a single institution experience. We did not compare our results with SVs used as aortocoronary conduits because our surgical strategy was to avoid aortic manipulation, if possible. During the study period, only 3 patients underwent isolated OPCAB using the SV for aortocoronary bypass. Third, this study was performed to analyze the SV composite grafts during the first postoperative year. Fourth, proportion of the IM area and the ratio of the IM thickness to the vessel diameter were slightly greater in the SV conduits than in the left ITA conduits, although not statistically significant. Long-term study might be necessary for a definite conclusion regarding the efficacy of SV composite grafts. Fifth, the results of the present study may not represent the entire patient population accurately, although there were no significant differences in the baseline characteristics between the 28 study patients and the other 115 patients. Sixth, we analyzed the impact of the number of distal anastomoses as representative of target burden. However, other variables such as the degree of stenosis, the size of the target coronary arteries, and conduit flow at the completion of anastomoses were not included in the analyses.

We wish to thank the Medical Research Collaborating Center, Seoul National University Hospital for statistical consultation.

\section{References}

1. Cox JL, Chiasson DA, Gotlieb AI. Stranger in a strange land: the pathogenesis of saphenous vein graft stenosis with emphasis on structural and functional differences between veins and arteries. Prog Cardiovasc Dis. 1991;34:45-68.

2. Cameron A, Davis KB, Green G, Schaff HV. Coronary bypass surgery with internal-thoracic-artery grafts - effects on survival over a 15-year period. N Engl J Med. 1996;334:216-20.

3. Kim K-B, Cho KR, Jeong DS. Midterm angiographic follow-up after off-pump coronary artery bypass: serial comparison using early, 1-year, and 5-year postoperative angiograms. J Thorac Cardiovasc Surg. 2008;135:300-7.
4. FitzGibbon GM, Kafka HP, Leach AJ, Keon WJ, Hooper GD, Burton JR. Coronary bypass graft fate and patient outcome: angiographic follow-up of 5,065 grafts related to survival and reoperation in 1,388 patients during 25 years. J Am Coll Cardiol. 1996;28:616-26.

5. Hwang HY, Kim JS, Kim K-B. Angiographic equivalency of off-pump saphenous vein and arterial composite grafts at one year. Ann Thorac Surg. 2010;90:516-21.

6. Hwang HY, Kim JS, Oh SJ, Kim KB. A randomized comparison of the Saphenous Vein Versus Right Internal Thoracic Artery as a Y-Composite Graft (SAVE RITA) trial: early results. J Thorac Cardiovasc Surg. 2012;144:1027-33.

7. Hwang HY, Kim M-A, Seo JW, Kim K-B. Endothelial preservation of the minimally manipulated saphenous vein composite graft: Histologic and immunochemical study. J Thorac Cardiovasc Surg. 2012;144:690-6.

8. Kim K-B, Cho KR, Chang WI, Lim C, Ham BM, Kim YL. Bilateral skeletonized internal thoracic artery graftings in off-pump coronary artery bypass: early result of Y versus in situ grafts. Ann Thorac Surg. 2002;74:S1371-6.

9. FitzGibbon GM, Leach AJ, Kafka HP, Keon WJ. Coronary bypass graft fate: angiographic grading of 1400 consecutive grafts early after operation and of 1132 after one year. J Am Coll Cardiol. 1991;17:1075-80.

10. Papaioannou TG, Stefandis C. Vascular wall shear stress: Basic principles and methods. Hellenic J Cardiol. 2005;46:9-15.

11. Mintz GS, Nissen SE, Anderson WD, Bailey SR, Erbel R, Fitzgerald PJ, et al. American College of Cardiology clinical expert consensus document on standards for acquisition, measurement and reporting of intravascular ultrasound studies (IVUS). A report of the American College of Cardiology task force on clinical expert consensus documents. J Am Coll Cardiol. 2001;37:1478-92.

12. Hong M-K, Mintz GS, Hong MK, Abizaid AS, Pichard AD, Satler LF, et al. Intravascular ultrasound assessment of the presence of vascular remodeling in diseased human saphenous vein bypass grafts. Am J Cardiol. 1999;84:992-8.

13. Hozumi T, Yoshikawa J, Yoshida K, Akasaka T, Takagi T, Honda Y, et al. Use of intravascular ultrasound for in vivo assessment of changes in intimal thickness of angiographically normal saphenous vein grafts one year after aortocoronary bypass surgery. Heart. 1996;76:317-20.

14. Higuchi Y, Hirayama A, Shimizu M, Sakakibara T, Kodama K. Postoperative changes in angiographically normal saphenous vein coronary bypass grafts using intravascular ultrasound. Heart Vessels. 2002;17:57-60.

15. Lau GT, Ridley LJ, Bannon PG, Wong LA, Trieu J, Brieger DB, et al. Lumen loss in the first year in saphenous vein grafts is predominantly a result of negative remodeling of the whole vessel rather than a result of changes in wall thickness. Circulation. 2006;114:I435-40.

16. Souza DSR, Johansson B, Bojö L, Karlsson R, Geijer H, Filbey D, et al Harvesting the saphenous vein with surrounding tissue for $\mathrm{CABG}$ provides long-term graft patency comparable to the left internal thoracic artery: results of a randomized longitudinal trial. J Thorac Cardiovasc Surg. 2006;132:373-8.

17. Tedoriya T, Kawasuji M, Sakakibara N, Ueyama K, Watanabe Y. Pressure characteristics in arterial grafts for coronary bypass surgery. Cardiovasc Surg. 1995;3:381-5.

18. Tsui JC, Souza DS, Filbey D, Bomfim V, Dashwood MR. Preserved endothelial integrity and nitric oxide synthase in saphenous vein grafts harvested by a 'no-touch' technique. Br J Surg. 2001;88:1209-15.

19. Gaudino M, Toesca A, Maggiano N, Pragliola C, Possati G. Localization of nitric oxide synthase type III in the internal thoracic and radial arteries and the great saphenous vein: a comparative immunohistochemical study. J Thorac Cardiovasc Surg. 2003;125:1510-5.

20. Johansson BL, Souza DS, Bodin L, Filbey D, Loesch A, Geijer H, et al. Slower progression of atherosclerosis in vein grafts harvested with 'no touch' technique compared with conventional harvesting technique in coronary artery bypass grafting: an angiographic and intravascular ultrasound study. Eur J Cardiothorac Surg. 2010;38:414-9.

21. Verma S, Lovren F, Pan Y, Yanagawa B, Deb S, Karkhanis R, et al. Pedicled no-touch saphenous vein graft harvest limits vascular smooth muscle cell activation: the PATENT saphenous vein graft study. Eur J Cardiothorac Surg. 2014;45:717-25.

22. Kulik A, Le May MR, Voisine P, Tardif J-C, De Larochelliere R, Naidoo S, et al Aspirin plus clopidogrel versus aspirin alone after coronary artery bypass grafting: the clopidogrel after surgery for coronary artery disease (CASCADE) trial. Circulation. 2010;122:2680-7.

23. Kim K-B, Hwang HY, Hahn S, Kim JS, Oh SJ. A randomized comparison of the Saphenous Vein Versus Right Internal Thoracic Artery as a Y-Composite Graft (SAVE RITA) trial: one-year angiographic results and mid-term clinical outcomes. J Thorac Cardiovasc Surg. 2014;148:901-8. 

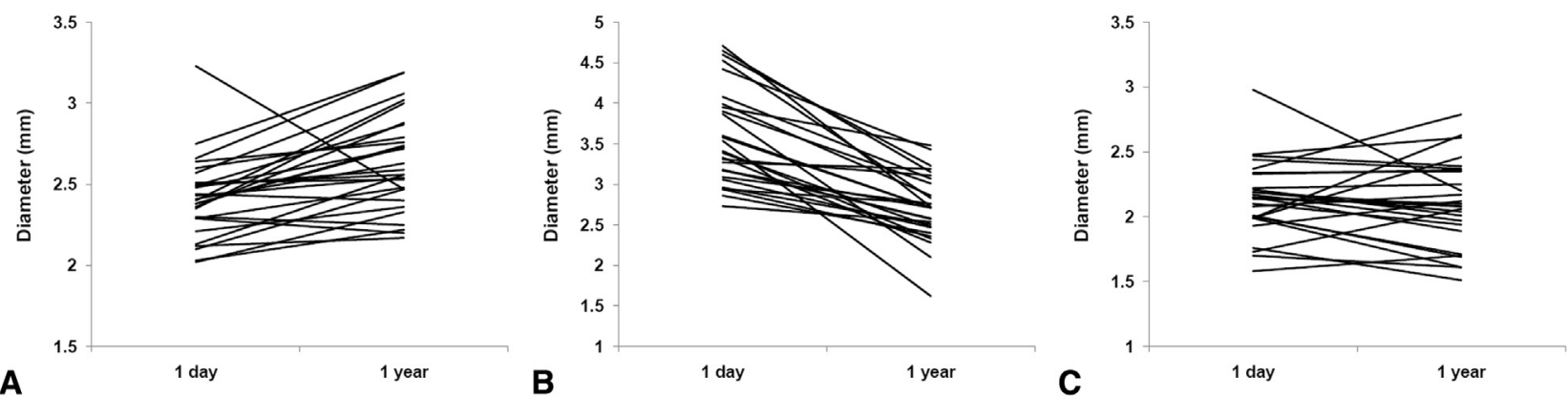

FIGURE E1. Changes in the diameter of the proximal internal thoracic artery (A), saphenous vein (B), and distal internal thoracic artery (C) 1 year after coronary artery bypass grafting.
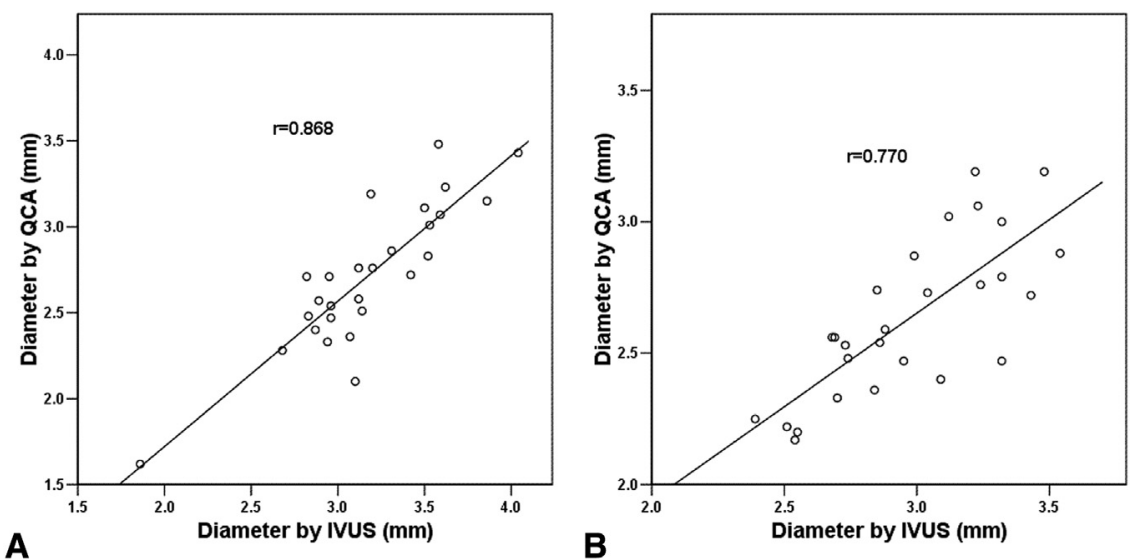

FIGURE E2. Correlations between the quantitative coronary angiography and intravascular ultrasound results for measurement of the luminal diameter of the saphenous vein (A) and proximal internal thoracic artery segments (B). QCA, Quantitative coronary angiography; IVUS, intravascular ultrasound.

TABLE E1. Results of quantitative coronary angiography analysis: changes in the luminal diameter of the saphenous vein and the proximal and distal internal thoracic artery segments in the 28 patients included in the study

\begin{tabular}{lccc}
\hline & $\begin{array}{c}\text { Early QCA } \\
(\mathbf{m m} \pm \mathbf{S D})\end{array}$ & $\begin{array}{c}\text { 1-year QCA } \\
(\mathbf{m m} \pm \mathbf{S D})\end{array}$ & $\boldsymbol{P}$ value \\
\hline Saphenous vein & & & \\
$\quad$ Maximum & $4.09 \pm 0.65$ & $3.19 \pm 0.45$ & $<.001$ \\
$\quad$ Minimum & $3.07 \pm 0.52$ & $2.24 \pm 0.49$ & $<.001$ \\
$\quad$ Mean & $3.58 \pm 0.61$ & $2.71 \pm 0.42$ & $<.001$ \\
Proximal ITA & & & \\
$\quad$ Maximum & $2.76 \pm 0.30$ & $2.94 \pm 0.37$ & $<.001$ \\
Minimum & $2.07 \pm 0.22$ & $2.34 \pm 0.29$ & $<.001$ \\
$\quad$ Mean & $2.41 \pm 0.25$ & $2.63 \pm 0.30$ & $<.001$ \\
Distal ITA & & & \\
$\quad$ Maximum & $2.61 \pm 0.38$ & $2.48 \pm 0.43$ & .178 \\
Minimum & $1.76 \pm 0.36$ & $1.69 \pm 0.37$ & .313 \\
Mean & $2.14 \pm 0.30$ & $2.10 \pm 0.35$ & .566 \\
\hline
\end{tabular}

$Q C A$, Quantitative coronary angiography; $S D$, standard deviation; ITA, internal thoracic artery. 